\title{
Using RealTime Physics with different instructional technologies in a circuits lab
}

\author{
Monica Quezada-Espinoza ${ }^{1}$, Angeles Dominguez ${ }^{2}$, and Genaro Zavala ${ }^{1}$

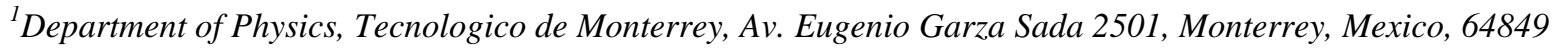 \\ 2 \\ Department of Mathematics, Tecnologico de Monterrey, Av. Eugenio Garza Sada 2501, Monterrey, Mexico, 64849
}

\begin{abstract}
Prior physics education studies have established a positive influence in learning when students use researchbased strategies (mainly Tutorials) and instructional technologies in physics courses. This contribution studies learning outcomes and behavior when combining a research-based strategy that promotes collecting data, RealTime Physics (RTP), with different instructional technologies: 1) RTP using probes and computers (original version), 2) RTP with probes and a graphing calculator, and 3) RTP with PhET simulations. Participants in this study were 271 engineering students enrolled in a private Mexican university who are familiar with the use of Tutorials in the physics lab. The experiment was conducted in the circuits unit of an Electricity and Magnetism course. This qualitative study uses a research-based open-ended test and systematic lab observations. Results show that student learning and behavior are related to the type of instructional technology used in combination with RTP in the lab activities.
\end{abstract}

\section{INTRODUCTION}

Previous work has demonstrated that students struggle to understand abstract physical concepts [1]. In the Physics Education Research (PER) field, many efforts have been made to improve conceptual learning in physics courses. Research-based strategies have shown to increase conceptual understanding [2]. A main emphasis of these strategies focuses on overcoming alternative conceptions [3] which have been studied extensively in PER [2]. An example of these strategies is Tutorials in Introductory Physics [4], which promote conceptual learning in a very effective way [5-7]. On the other hand, the PER community has worked on instructional technologies that are used to foster students' understanding of abstract concepts [2]. An example of these technologies is PhET sims, open-source simulations in areas of science [8].

There have been some efforts to combine PER-based strategies and instructional technologies to improve the learning of abstract concepts in electricity and magnetism $[9,10]$. In a previous study [11], we used the Framework for Simulation Use in Educational Settings [12] with Tutorials and PhET sims for learning circuits to establish their positive influence in student learning. For this contribution, we adapt the same framework to use another research-based strategy, RealTime Physics (RTP) [13], and other kinds of technology: probes to collect data with the use of computer and graphing calculator. The objective for this study is to analyze student conceptual learning and behavior when they manipulate different instructional technologies during a lab activity combined with a research-based strategy, in this case RealTime Physics. The research question behind this qualitative study is how do different instructional technologies play a role in students' conceptual learning and behavior while working with RealTime Physics?

\section{BACKGROUND}

RTP is a research-based strategy that promotes active learning through the use of probes to collect and analyze data [13]. According to Sokoloff [14], the main characteristics of RTP are: (1) use of a learning cycle to compare students' working groups predictions of physical phenomena, (2) use of guided hands-on work to construct basic concepts from observations, and (3) use of computerbased tools. This study uses RTP as the research-based strategy to promote learning.

Alternative conceptions [3] in electric circuits have been extensively investigated and documented. Taşlidere [15] reports a categorization that describes the sink model, the attenuation model, the shared current model, the sequential model, the clashing current model, the empirical rule model, the short circuit misconception, the power supply as constant current source, the parallel circuit misconception, local reasoning, and current flow as water flow. This study evaluates the majority of these alternative conceptions.

A variety of instructional technologies reported by Docktor and Mestre [2], such as classroom polling technologies, multimedia presentations, computer data collection and analysis tools, and computer programming, 
have been used within the PER community. This study evaluates three combinations: a) probes, interface, and computer; b) probes, lab cradle, and graphing calculator; and c) PhET interactive sims.

Based on the framework of Rehn et al. [12] and the alternative conceptions [15], this study will add to the understanding of how the use of the RTP strategy combined with the use of different instructional technologies influence on students' conceptual learning and behavior. For the purpose of this article and space limitations we focus on observations findings. A more deeply analysis of conceptual learning will be reported in future investigations.

\section{METHODOLOGY}

The students in this experiment $(\mathrm{N}=271)$ were enrolled in in an introductory Electricity and Magnetism course for engineering students. The course's format is a semester with two 90-min. lectures and one 90-min. laboratory session per week. The study was set in the lab session in which students regularly use Tutorials [4] guided by senior lab instructors, most of them undergraduate Physics Engineering students. A laboratory session consists of 4 groups of 4 students each $( \pm 1$ student). Data collection was carried out by two methods: one problem on an exam and observations of the students while working on two lab activities.

\section{A. Research-based strategies}

The study uses two DC circuits RealTime Physics activities: Current in simple DC circuits (Lab 2) and Voltage in simple DC circuits and Ohm's law (Lab 3) [13]. With these activities students explore the relationships between current and potential difference in different parts of series and parallel circuits constructed from bulbs, resistors, and batteries. An adapted RTP was implemented to test different instructional technologies. There were three variations of RTP: (1) the original version, using probes, interface, and computer software (RTPc); (2) using probes, lab cradle, and graphing calculator (RTPTi); and (3) using PhET interactive simulations (RTPhet). These adaptations were retrieved in Spanish from a previous publication [16]. Students with the first two variations (RTPc and RTPTi) used current and voltage probes to do their measurements. In the case of RTPhet, students used simulated bulbs, resistors and batteries included in the simulation, as well as voltage probes to do their measurements. Twenty out of 26 lab sections of the Electricity and Magnetism course participated in this study. Each section had an average of 14 students. The variation of RTP implemented was assigned randomly and kept unchanged for the two lab sessions that the experiment lasted. That is, those students working with one variations of RTP in the first circuit lab, continued working with the same equipment for the second circuit lab.
Notice that all students from the same lab section worked with the same technology; randomness was between sections, not between students.

\section{B. Open-ended test problem}

This study uses a problem [11] that consists of six openended conceptual questions. This problem was included in the second evaluation that occurred one week after the circuits lab activities and was applied in the lecture part of the course. Figure 1 shows the problem's main circuit.

From all students who participated in the activities, only a fraction of them answered this problem since only a few lecture instructors allowed us to include the problem in their test. However, the number of students working with each variation of RTP who took the test was balanced, i.e., 25 students worked with RTPc, 23 students worked with RTPTi, and 27 students used RTPhet.

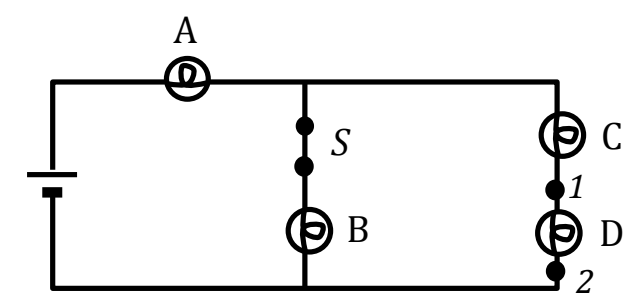

FIG. 1. Main circuit of the six-part open-ended problem.

The open-ended problem was designed and analyzed to detect specific alternative conceptions through students' reasoning. These alternative conceptions are described as follows (more details of individual studies in refs. [11, 14, 16]): (a) the sequential model, in which it is assumed that a change at a point in an electrical circuit affects the circuit forward in the direction of the current, not backward; (b) the short-circuit model, in which a wire without electrical devices connected is ignored when analyzing an electrical circuit; (c) the power supply as constant-current source model, in which any power supply is considered to provide a constant current to a circuit; (d) the local reasoning model, in which in case of a change in a circuit, students focus on local changes instead of on a global analysis; (e) the attenuation model, in which an electric current traveling around an electrical circuit in one direction is thought to decrease gradually due to consumption of it by devices within the circuit; and (f) the short circuit misconception, in which a wire without electrical devices connected is ignored when analyzing an electrical circuit. Design and analysis of the open-ended test were based on these conceptions.

\section{Observation}

The participants of the study $(\mathrm{N}=271)$ were observed by the same person during the two lab sessions that the 
experiment lasted. To register the students' behavior and interactions during the activities, the researcher used a rubric to evaluate a set of collaborative group skills: (1) keep on task, (2) contribute ideas towards solving the problem, and (3) collaboration levels. These levels were chosen according to two of active learning's main characteristics: engagement and collaboration [17]. The first three skills were registered three times during the lab session: at the beginning, middle, and end of the activity. Students' skills were evaluated on a five-level Likert scale, e.g., keep on task level was evaluated from completely distracted (1) to completely focused (5). Further, the observer kept notes about the general use of the RTP strategy and student roles.

\section{RESULTS}

\section{A. Conceptual learning}

Conceptual learning was analyzed qualitatively based on students' responses to a six-part open-ended problem included on an exam. Students' responses were coded and categorized according to the alternative conceptions described in the open-ended test problem section of this article.

Students, using a research-based strategy with an instructional technology, still had difficulties to overcome alternative conceptions in DC circuits as has been proved before $[9-11,16]$. Since the number of students are approximately the same and all of them responded the same problem, we can hypothesize that RTPc and RTPTi might have been able to better foster learning although differences are not quite large.

Looking at the type of alternative conceptions more reported by students in the three different groups (students who used RTPc incur 44 times in the use of an alternative conception, students who used RTPTi, 49, and students used RTPhet, 63), we found that students who used RTPhet and RTPTi report more frequently the alternative conceptions called attenuation model (in which an electric current traveling around an electrical circuit in one direction is thought to decrease gradually due to consumption of it by devices within the circuit) and the short circuit misconception (in which a wire without electrical devices connected is ignored when analyzing an electrical circuit). On the other hand, students who used RTPc report with more frequency the conceptions called the power supply as constant-current source model (in which any power supply is thought to provide a constant current to a circuit) and the sequential model (in which it is assumed that a change at a point in an electrical circuit affects the circuit forward in the direction of the current, not backward) [15].

\section{B. Observation}

Figure 2 summarizes results obtained for every skill observed during the circuits lab activities (keep on task, focus level; contribute ideas towards solving the problem, discussion, and collaboration). Each bar in the stacked bar graph represents the moment of the observation (at the beginning, middle or end); each bar layers the average obtained for each skill observed (focus, discussion, and collaboration). The first three bars belong to RTPc findings, the second third to RTPTi, and last third, to RTPhet.

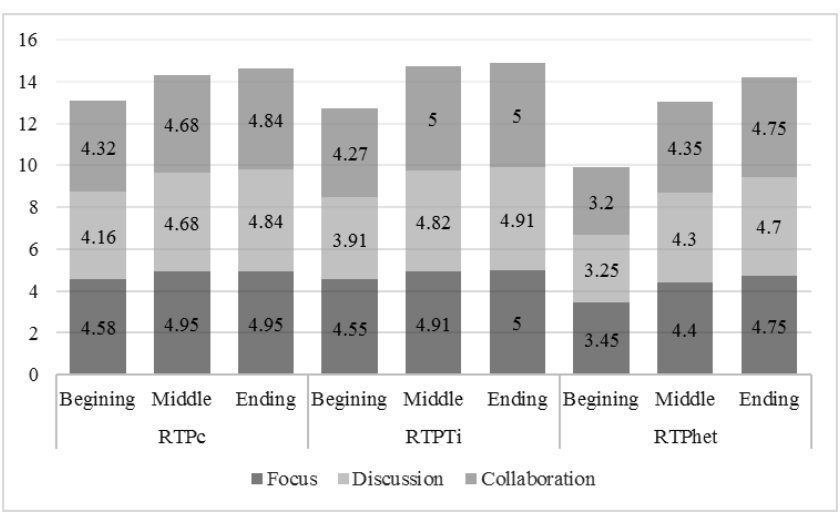

FIG. 2. Stacked bar graph for observation results.

Focus: Students who used the original version of RealTime Physics, RTPc (with probes and computer interface) and those who used RTP with graphing calculator and probes (RTPTi) were focused in a high level from the beginning to the end of the activity. Focus level for those students who use PhET sims had a low start at the beginning of the activity, but they improve at the end, achieving a high focus level. Briefly, we can say that the use of probes to collect data helped students to stay focused all the time during the lab activities.

Discussion: We can see that students using RTPc and RTPTi behave similarly at the end of the activity having a higher level of discussion than that at the beginning of the activity; however, during the whole activity they had a high level of discussion. Students who use RTPhet had similar behavior in terms of having a better level at the end of the activity than at the beginning; however, the level of discussion for these students is lower than those for RTPc and RTPTi. In general, we hypothesize that the use of probes to collect data promotes more discussion among peers than the use of PhET sims.

Collaboration: As in focus and discussion levels, the collaboration observed among students while they performed their lab activities seems to have a relation with the kind of technology used. Students who used probes to collect data, either with computer or with calculator, had higher collaboration levels from the beginning to the end of the activity than students who used PhET sims. 
Nevertheless, students who used PhET sims scored a high level of collaboration from the middle to the end of the activity. The great difference is that it seems that the use of calculator promotes more collaborative skills than the use of the computer.

\section{DISCUSSION AND CONCLUSIONS}

The objective for this study was to analyze student conceptual learning and behavior when they manipulate different instructional technologies during a lab activity combined with a research-based strategy, in this case RealTime Physics. To reach that objective we based our implementation on the Rehn et al. [12] Framework for Simulation Use in Educational Settings for different instructional technologies (adapted in the case of the use of equipment). The three elements in our implementation were: (1) the Environment element, which consisted of a laboratory provided with an instructor, lab equipment, and tables to work collaboratively, (2) the Instructional Technology element, the PhET simulation, probes to collect data, computers and graphing calculators, and (3) the Assignment element, the adaptation of a research-based strategy, RealTime Physics.

In general, it was found that this combination of elements for different kinds of instructional technologies promotes that students reach an optimum level of focus, discussion and collaboration at the end of the activities. However, based on our results, we can hypothesize that students who collect data in real time with the different equipment (computer and graphing calculator) have higher levels of the evaluated skills than those who use the PhET sims. Moreover, based on our results, we can also hypothesize that those skills are related to students' learning, that is, students with the highest levels of focus, discussion, and collaboration skills, have overcome more alternative conceptions at the end of the activities. We believe that our work presents some evidence for those hypotheses but the results are not conclusive.

Evidence of the positive impact of well-guided use of technology (simulations) has been documented [10, 12]. However, we found that there might a difference between the types of instructional technologies that have an effect on students' learning. We have some evidence that when students manipulate lab materials (bulbs, batteries, wires, etc.), collect and analyze data, and observe directly the physical phenomena (current and voltage in a circuit) they become more engaged. That is, when students are physically and mentally engaged during the lab activity, they have a better understanding of physical concepts, and these actions are well promoted with the use of RealTime Physics.

\section{ACKNOWLEDGEMENTS}

The authors want to acknowledge the help of the Department of Physics of the university of this study was done. Especially, we would like to thank Rodolfo Rodriguez, Department Chair, Quetzal Garcia, general lab coordinator, Francisco Rodriguez, Electricity and Magnetism coordinator, lecture instructors who agreed to use an exam problem provided by the authors and all lab instructors who participated coordinating the lab activities.
[1] M. R. Stetzer, P. van Kampen, P. S. Shaffer, P. S., and L. C. McDermott, Am. J. Phys., 81, 2, (2013).

[2] J. L. Docktor and J. P. Mestre, (2014). Phys. Rev. ST Phys. Educ. Res., 10, 2, (2014).

[3] D. Hammer, Am. J. Phys., 64, 10, (1996).

[4] L. C. McDermott, P. S. Shaffer, and the Physics Education Group, Tutorials in Introductory Physics (Prentice-Hall, Englewood Cliffs, NJ, 1998).

[5] P. Godoy, J. Benegas, and S. Pandiella, LAJPE, 6, 1, (2012).

[6] M. H. P. Kesonen, M. A. Asikainen, and P. E. Hirvonen, Eur. J. Phys., 34, 4, (2013).

[7] H. V. Mauk and D. Hingley, Am. J. Phys., 73, 12, (2005).

[8] C. Wieman, W. Adams, P. Loeblein, and K. Perkins. Phys. Teach., 48, 225, (2010).

[9] G. Zavala and J. J. Velarde in X Congreso Nacional de Investigación Educativa (Veracruz, Mex, 2009), p. 113.
[10] C. J. Keller, N. D. Finkelstein, K. K. Perkins, and S. J. Pollok in AIP Conference Proceedings (Salt Lake City, Utah, 2006) p. 109-112.

[11] M. Quezada-Espinoza, V. del Campo, and G. Zavala, in Physics Education Research Conference

Proceedings, edited by A. D. Churukian, D. L. Jones, and L. Ding (College Park, MD, 2015), p. 271.

[12] D. A. Rehn, E. B. Moore, N. S. Podolefsky and N. D. Finkelstein, JoTLT, 2, 1, (2013).

[13] D. R. Sokoloff, R. K. Thornton, and P. Laws, RealTime Physics, Active learning laboratories (New York: John Wiley \& Sons, Inc, 2004).

[14] D. R. Sokoloff. Phys. Teach., 54, 1, (2016).

[15] E. Taşlıdere, E., CE, 4, 4, (2013).

[16] M. Quezada-Espinoza and G. Zavala, LAJPE, 8, 4, (2014).

[17] J. M. Fraser, A. L. Timan, K. Miller, J. E. Dowd, L. Tucker, and E. Mazur (2014). Reports on Progress in Physics. Physical Society (Great Britain), 77,3, (2014). 